\title{
MODIFIED ULTRAFILTRATION IMPROVES LEFT VENTRICULAR SYSTOLIC FUNCTION IN INFANTS AFTER CARDIOPULMONARY BYPASS
}

Michael J. Davies, FRCS ${ }^{\mathrm{a}}$

Khan Nguyen, $\mathrm{MD}^{\mathrm{a}}$

J. William Gaynor, $\mathrm{MD}^{\mathrm{b}}$

Martin J. Elliott, MD

Sponsor:

Marc R. de Leval, MD, FRCS
Objective: Our objective was to test the hypothesis that use of modified ultrafiltration after cardiopulmonary bypass improves intrinsic left ventricular systolic function in children. Methods: Twenty-one infants undergoing cardiopulmonary bypass were instrumented with ultrasonic dimension transducers, to measure the anteroposterior minor axis diameter, and a left ventricular micromanometer. Patients were randomized to modified ultrafiltration ( $n=11$, age $226 \pm 355$ days, weight $6.7 \pm 3.1 \mathrm{~kg}$ ) or control ( $n=10$, age $300 \pm 240$ days, weight $7.0 \pm 2.5 \mathrm{~kg}$ ) (all differences $p>0.05$ between groups). Left ventricular systolic function was assessed by means of the slope of the preload-recruitable stroke work index. Myocardial cross-sectional area was measured by echocardiography. Data were acquired immediately after separation from bypass, at steady state, and during transient vena caval occlusion. Data acquisition was repeated after $13 \pm 5$ minutes of modified ultrafiltration or after $12 \pm 5$ minutes without modified ultrafiltration in the control group. Inotropic drug support was the same at both study points. Results: In the modified ultrafiltration group, the filtrate volume was $363 \pm 262 \mathrm{ml}$. The hematocrit value increased from $26.0 \% \pm 2.7 \%$ to $36.7 \% \pm 9.5 \%(p=0.018)$, myocardial cross-sectional area decreased from $3.72 \pm 0.35 \mathrm{~cm}^{2}$ to $3.63 \pm 0.36 \mathrm{~cm}^{2}(p=0.04)$, end-diastolic length increased from $25.6 \pm 9.0 \mathrm{~mm}$ to $28.8 \pm 9.9 \mathrm{~mm}(p=0.01)$, and end-diastolic pressure fell from $5.6 \pm 0.8 \mathrm{~mm} \mathrm{Hg}$ to $4.2 \pm 0.8 \mathrm{~mm} \mathrm{Hg}(p=$ 0.005), suggesting an improved diastolic compliance. In the control group, the hematocrit value, myocardial cross-sectional area, end-diastolic length, and pressure did not change (all $p>0.05$ ). Mean ejection pressure increased in the ultrafiltration group $(p=0.001)$ but did not change in the control group $(p=\mathbf{0 . 2 2})$. The slope of the preload-recruitable stroke work index increased after ultrafiltration from $52.3 \pm 52.0$ to $74.2 \pm 66.0\left(10^{3}\right.$ $\left.\mathrm{erg} / \mathrm{cm}^{3}\right)(p=0.02)$ but did not change in the control group $(p=0.07)$. One patient from each group died in the postoperative period. Patients in the ultrafiltration group received less inotropic drug support in the first 24 hours after the operation $(156.62 \pm 92.31 \mu \mathrm{g} / \mathrm{kg}$ in 24 hours $)$ than patients in the control group $(865.33 \pm 1772.26 \mu \mathrm{g} / \mathrm{kg}$ in 24 hours, $p=0.03)$. Conclusions: Use of modified ultrafiltration after cardiopulmonary bypass improves intrinsic left ventricular systolic function, improves diastolic compliance, increases blood pressure, and decreases inotropic drug use in the early postoperative period. (J Thorac Cardiovasc Surg 1998;115:361-70)
From the Great Ormond Street Hospital for Children NHS Trust, London, United Kingdom, ${ }^{\mathrm{a}}$ and the Childrens Hospital of Philadelphia, Philadelphia, Pa. ${ }^{\text {b }}$

Read at the Seventy-seventh Annual Meeting of The American Association for Thoracic Surgery, Washington, D.C., May 4-7, 1997.

Received for publication May 7, 1997; revisions requested June 9,
1997; revisions received Oct. 23, 1997; accepted for publication Oct. 23, 1997.

Address for reprints: Michael J. Davies, FRCS, Cardiothoracic Unit, Great Ormond Street Hospital for Children NHS Trust, London WC1N 3JH, United Kingdom.

Copyright (C) 1998 by Mosby, Inc.

$0022-5223 / 98 \$ 5.00+0 \quad \mathbf{1 2} / \mathbf{6} / \mathbf{8 7 2 2 4}$ 
C ardiopulmonary bypass (CPB) with hypothermia and crystalloid hemodilution in children is associated with an inflammatory capillary leak, ${ }^{1,2}$ which results in an increase in tissue water content, manifest as an increase in total body water after cardiac operation. ${ }^{3-7}$ The increase in total body water, most marked in small babies undergoing prolonged periods of CPB with hemodilution, ${ }^{2}$ is associated with tissue edema and subsequent organ dysfunction. Cardiac and pulmonary edema have been well described after cardiac operations ${ }^{8,9}$ and may influence postoperative morbidity. Modified ultrafiltration, performed after $\mathrm{CPB}$, has been shown to reduce total body water and reverse hemodilution, as well as to increase hematocrit value, cardiac index, and systolic blood pressure. ${ }^{7,10}$ Modified ultrafiltration has been shown to reduce the inflammatory response associated with CPB by altering circulating cytokines, ${ }^{11}$ as well as to reduce myocardial edema. ${ }^{12}$ However, the mechanism underlying the improvement in hemodynamics has not yet been determined. This study was designed to test the hypothesis that the improvement in hemodynamic parameters seen after use of post-CPB modified ultrafiltration is due to an improvement in intrinsic left ventricular systolic function measured by means of a load-independent index of contractility.

\section{Methods}

Approval for the study was obtained from The Great Ormond Street Hospital NHS Trust and Institute of Child Health Ethical Committee before commencement. Informed consent was obtained from the parents of all infants enrolled in the study.

Twenty-one infants were enrolled in the study. All were to undergo cardiac operations for correction of congenital heart defects by the same surgeon (M.J.E.). The patients were prospectively randomized into two groups: a control group $(n=10$, age $300 \pm 240$ days, weight $7.0 \pm 2.5 \mathrm{~kg}$ ) and a group who underwent modified ultrafiltration (MUF group; $n=11$, age $226 \pm 355$ days, weight $6.7 \pm 3.1$ $\mathrm{kg})$.

Anesthetic techniques. After premedication with atropine, anesthesia was induced with cyclopropane 50\% inhalation over a 2-minute period, and fentanyl (18 to 56 $\mu \mathrm{g} / \mathrm{kg}$ ) was given as clinically indicated. Mechanical ventilation to normocapnia, initially with nitrous oxide in oxygen and proceeding to $100 \%$ oxygen, was facilitated by paralysis with pancuronium bromide at an initial dose of $0.15 \mathrm{mg} / \mathrm{kg}$ followed by $0.725 \mathrm{mg} / \mathrm{kg}$ at 40 -minute intervals. Anesthesia was maintained with intravenous fentanyl (20 to $50 \mu \mathrm{g} / \mathrm{kg}$ ) and isoflurane (0.5\% to $1.0 \%$ ) as appropriate. Blood pressure was controlled, if necessary, with phentolamine, methoxamine, or sodium nitroprusside. Patients were weaned from $\mathrm{CPB}$ on a regimen of dopamine 0 to 15 $\mu \mathrm{g} / \mathrm{kg}$ per minute and nitroprusside as required.
Data acquisition and experimental protocol. The CPB techniques used, which are summarized below, reflected the common practices in our unit and have been described in detail elsewhere. ${ }^{10}$ After a median sternotomy, CPB was performed with a nonpulsatile roller pump (Stöckert, Munich, Germany). For flow rates of less than 1500 $\mathrm{ml} / \mathrm{min}$, a Shiley-Dideco 701 hollow-fiber oxygenator (Sorin Biomedica, Saluggio, Italy) was used; for flow rates greater than $1500 \mathrm{ml} / \mathrm{min}$, a Maxima hollow-fiber oxygenator (Medtronic Electromedics HemoTec, Inc., Parker, Colo.) was used. The circuit was primed as described previously. ${ }^{10}$

A 3F micromanometer-tipped catheter (model SPC330, Millar Instruments, Inc., Houston, Tex.) was zeroed to atmospheric pressure and electronically calibrated before being placed in the mid-left ventricular cavity via the roof of the left atrium. A tape was then passed around the inferior vena cava for vena caval occlusion.

CPB was initiated before the heart was instrumented. Pulse-transit ultrasonic dimension transducers $(1.5 \mathrm{~mm}$ outer diameter cylinder, Physiological Monitoring Systems Group, Duke University Medical Center, Durham, N.C.) were positioned across the anteroposterior minor axis diameter of the left ventricle as previously described. ${ }^{13-15}$ In brief, the anterior crystal was sutured adjacent to the left anterior descending artery, half way between the apex and base of the ventricle, and the posterior crystal was positioned adjacent to the posterior descending coronary artery directly opposite the anterior crystal. The patient was cooled and surgical correction of the congenital heart defect was carried out according to the methods previously described from our unit. ${ }^{16}$ Myocardial preservation was achieved with cold crystalloid St. Thomas' Hospital solution in a dose of 20 to $30 \mathrm{ml} / \mathrm{kg}$ initially and 10 to $15 \mathrm{ml} / \mathrm{kg}$ every 30 minutes.

Rewarming was achieved by arteriovenous heat exchange together with a warming blanket and heated humidified inspired gases. A gradient of less than $10^{\circ} \mathrm{C}$ was maintained between the blood and the water in the heat exchanger. Sodium nitroprusside (5 to $10 \mu \mathrm{g} / \mathrm{kg}$ per minute) was used as a vasodilator during rewarming but was stopped 3 to 5 minutes before cessation of CPB.

After separation from CPB, and after a brief period of stabilization, data were acquired at steady state and during transient vena caval occlusion (T1, see below).

In those patients randomized to the MUF group, ultrafiltration was commenced as described below. In patients randomized to the control group, no intervention was allowed so long as the patient remained in a stable condition. In the MUF group, data acquisition was repeated after $13 \pm 5$ minutes of modified ultrafiltration (T2, see below). In the control patients, data acquisition was repeated after $12 \pm 5$ minutes (T2, see below). Inotropic drug support was not altered between the T1 and T2 study points.

At each of the study time points (T1 and T2), myocardial cross-sectional area and left ventricular posterior wall thickness were measured by epicardial echocardiography (Acuson 128XP-10C, Acuson Corp., Mountain View, Calif.). Views of the left ventricular minor axis were taken at the level of the papillary muscle. Left ventricular posterior wall thickness (h) was measured directly by the 
integrated software of the system. Myocardial cross-sectional area was measured at each time point by means of a custom-made digital subtraction technique.

On return to the pediatric intensive care unit, standard clinical observations were maintained with particular reference to the inotropic support required during the first 24 hours, the ventilation period, and the number of days in the intensive care unit. For between-group comparison, a total dose of inotropic drugs during the first 24 hours was calculated by adding the doses of dopamine and dobutamine in micrograms per kilogram per minute and assigning an arbitrary equivalent value of $10 \mu \mathrm{g}$ inotropic drugs per kilogram per minute for each $0.1 \mu \mathrm{g}$ of epinephrine per kilogram per minute and $10 \mu \mathrm{g} / \mathrm{kg}$ per minute for each $1 \mu \mathrm{g}$ of milrinone per kilogram per minute. ${ }^{17}$ Heart rate, arterial blood pressure, and atrial pressures were recorded continuously throughout the study period.

Modified ultrafiltration. Ultrafiltration was carried out in the MUF group for the first $13 \pm 5$ minutes after cessation of $\mathrm{CPB}$ by the modified method previously described $^{7,10}$ and briefly described below. A Gambro FH66 ultrafilter (Gambro, Dialysatoren GmbH \& Co KG, D-7450, Hechingen, Germany) was used in all cases.

In the modified ultrafiltration technique (Fig. 1), the ultrafilter is placed with its inlet connected to the arterial line and the outlet to the venous line. The CPB circuit, including the ultrafilter, is then primed. During CPB the inlet of the filter is kept clamped. When the patient is weaned from $\mathrm{CPB}$, the outlet of the ultrafilter is fed to the right atrium of the patient via a Hot Line L70 (Level 1 Technologies, Rockland, Mass.). The venous blood is chased back to the venous reservoir with saline solution. The inlet of the ultrafilter is unclamped and arteriovenous ultrafiltration is carried out. The blood flow through the ultrafilter is about $200 \mathrm{ml} / \mathrm{min}$, which is maintained by a roller pump on the inlet aspect of the ultrafilter (Fig. 1). Suction is applied to the filter port $(-125 \mathrm{~mm} \mathrm{Hg})$ to achieve an ultrafiltration rate of 100 to $150 \mathrm{ml} / \mathrm{min}$. A constant left atrial pressure is maintained by giving volume from the venous reservoir back to the patient via the ultrafilter, thus hemoconcentrating the fluid in the circuit. When the level in the venous reservoir is low, crystalloid is added to the reservoir to keep it primed. Ultrafiltration was carried out until a hematocrit value of approximately $40 \%$ was reached.

Data acquisition. The ultrasonic dimension transducers were coupled to a sonomicrometer (Physiological Monitoring Systems Group, Duke University Medical Center, Durham, N.C.) and electronically calibrated. The ultrasonic signals, left ventricular pressure, arterial pressure, and electrocardiogram were displayed on a video display monitor.

After separation of the patient from CPB, and after a period of stabilization, data were collected under steadystate conditions and under transient caval occlusion, during which the patient was briefly disconnected from the ventilator (T1). After modified ultrafiltration or an equivalent time period in the control group, data acquisition was repeated (T2). Physiologic data collected under steady-state conditions included heart rate, left ventricular posterior wall thickness (h), left ventricular dimensions, and pressure. Minor axis epicardial length $\left(\mathrm{L}_{\mathrm{epi}}\right)$

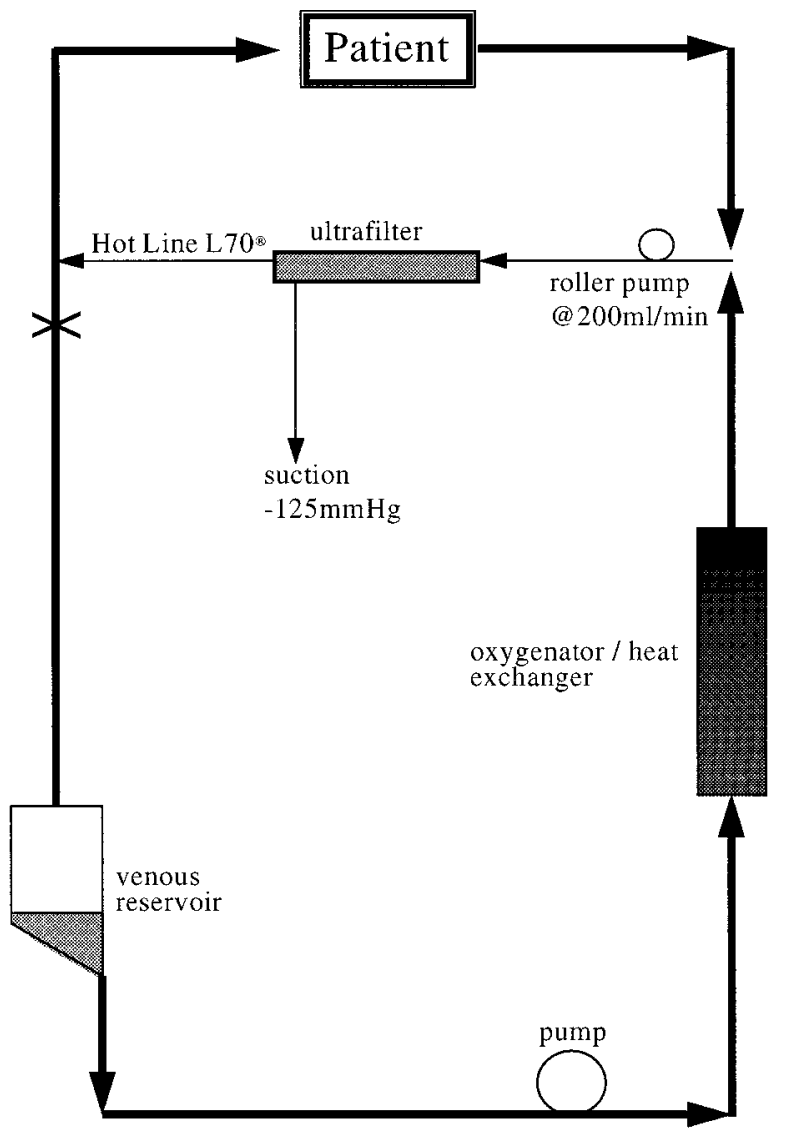

Fig. 1. Circuit setup for modified ultrafiltration.

and mean ejection pressure were determined directly from the collected data.

Vena caval occlusion was performed by gently and progressively compressing the inferior vena cava for 10 to 15 seconds. Only caval occlusions that produced a fall in left ventricular systolic pressure of at least $30 \mathrm{~mm} \mathrm{Hg}$ were analyzed. Premature beats and the subsequent beat were excluded from analysis.

Data analysis. Analog data were digitized in real time at 200 samples per second with the use of a personal computer-based data acquisition system (DMDAS, Medical Research Technology, Reston, Va.) and analyzed on a personal computer (Digital Celebris 590, Digital Equipment Corporation, Maynard, Mass.) with DMDAS software.

The first derivative of left ventricular pressure $(\mathrm{dP} / \mathrm{dt})$ was computed from the digital pressure waveform as a running five-point polyorthogonal transformation. ${ }^{13}$ The cardiac cycle was defined automatically with the DP/DT. End-systole was defined as occurring at the peak negative pressure derivative. ${ }^{13}$ End-diastole was defined automatically $40 \mathrm{msec}$ before a positive DP/DT greater than 500 $\mathrm{mm} \mathrm{Hg} / \mathrm{sec}$, and this definition was checked visually for every beat with a videographics display system. ${ }^{13}$ The requirement for redefinition was rare according to the criteria listed above. 
Table I. Patient demographics

\begin{tabular}{lccc}
\hline & MUF group & Control group & $p$ Value \\
\hline Patients & 11 & 10 & - \\
Age (days) & $226 \pm 355$ & $300 \pm 240$ & 0.57 \\
Weight (kg) & $6.7 \pm 3.1$ & $7.0 \pm 2.5$ & 0.81 \\
Sex (M/F) & $8: 3$ & $7: 3$ & - \\
\hline
\end{tabular}

MUF, Modified ultrafiltration. $p$ Value, unpaired $t$ test, MUF group versus control group.

Left ventricular epicardial minor axis diameter (length) was collected directly by the DMDAS software throughout the cardiac cycle. Intracavity (endocardial) length (L) was calculated according to the formula ${ }^{15}$

$$
\mathrm{L}=\mathrm{L}_{\text {epi }}-2 \mathrm{~h}
$$

This value of endocardial length (L) was used for all subsequent data analyses (see below).

Left ventricular stroke work index $\left(\mathrm{SW}_{\mathrm{i}}\right)$ was calculated by point-by-point integration of the pressure-intracavity length loop over each cardiac cycle ${ }^{13}$ :

$$
\mathrm{SW}_{\mathrm{i}}=\int \mathrm{P} \cdot \mathrm{dL}
$$

The preload-recruitable stroke work index relation was determined by linear regression analysis of the stroke work index and the corresponding intracavity end-diastolic length data obtained during each caval occlusion, according to the formula:

$$
\mathrm{SW}_{\mathrm{i}}=\mathrm{M}_{\mathrm{w}}\left(\mathrm{EDL}-\mathrm{L}_{\mathrm{w}}\right)
$$

where $\mathrm{M}_{\mathrm{w}}$ is the slope and $\mathrm{L}_{\mathrm{w}}$ the $\mathrm{x}$-axis intercept of the preload-recruitable stroke work index relation. ${ }^{13}$

Statistical analysis. Results are summarized as mean \pm one standard deviation. For hemodynamic descriptors of ventricular performance that did not require variably loaded pressure-length loops, the mean values at each level were calculated.

Changes in physiologic measurements (heart rate, enddiastolic length, end-diastolic pressure, mean ejection pressure, and stroke work index) were assessed by means of paired $t$ tests to compare steady-state values at times T1 and T2 and unpaired $t$ tests to compare between the MUF and control groups.

Comparisons of slope, length-axis intercept, and coefficient of variation at the different time points and between the MUF and control groups were made using paired and unpaired $t$ tests.

\section{Results}

As shown in Table I, the MUF group and control group were well matched for age, weight, and sex distribution. Both groups underwent similar operations, the most frequent being repair of ventricular septal defect (Table II). The patients in the MUF group tended toward longer CPB and crossclamp times, but these failed to reach statistical significance (Table II). In the MUF group, the filtrate volume was $363 \pm 262 \mathrm{ml}$ and the hematocrit value increased from $26.0 \% \pm 2.7 \%$ when coming off $\mathrm{CPB}$ (T1) to $36.7 \% \pm 9.5 \%$ after MUF (T2, $p=0.018$ ). In the control group, the hematocrit value did not change between T1 and T2 ( $p=0.08$, Table II).

Heart rate did not change significantly between T1 and T2 in either group (Table III). End-diastolic length increased $(p=0.01)$ and end-diastolic pressure fell $(p=0.005)$ after modified ultrafiltration, suggesting an improvement in diastolic compliance. These values did not change significantly in the control group (Table III). At time T1, the mean ejection pressure for those patients in the MUF group was significantly lower than for those patients in the control group ( $p=0.02$, Table III). Without any change in the inotropic support, the mean ejection pressure increased $13 \pm 10 \mathrm{~mm} \mathrm{Hg}$ in those patients who underwent modified ultrafiltration ( $p=0.001$, Table III, Fig. 2$)$ and fell $14 \pm 8 \mathrm{~mm} \mathrm{Hg}$ in the control group between T1 and T2 $(p=0.22$, Table III, Fig. 2), such that there was no significant difference between the groups at the end of the operation.

Left ventricular posterior wall thickness $(p=$ $0.66)$ and myocardial cross-sectional area $(p=0.02)$ were both greater at T1 in the MUF group than the control group (Table III). Both left ventricular posterior wall thickness and myocardial cross-sectional area decreased after modified ultrafiltration (both $p=0.04$ ), suggesting a reduction in myocardial edema (Table III). Left ventricular wall thickness and myocardial cross-sectional area remained constant in the control group (Table III).

The preload-recruitable stroke work index tended to be lower at T1 in the MUF group than in the control group ( $p=0.053$, Table IV). After modified ultrafiltration, the slope of the preload-recruitable stroke work index increased from $52.3 \pm 52.0$ to $74.2 \pm 66.0\left(10^{3} \mathrm{erg} / \mathrm{cm}^{3}\right)(p=0.02)$, but did not change in the control group (Fig. 2 and Table IV). The $\mathrm{x}$-intercept $\left(\mathrm{L}_{\mathrm{w}}\right)$ did not change in either group (Table IV). A representative set of pressure-dimension loops recorded during vena caval occlusion is shown in Fig. 3, along with representative preloadrecruitable stroke work index changes between times T1 and T2 for the MUF and control groups.

One patient from each group died in the 30-day postoperative period. The patient from the MUF group died 3 days after the arterial switch operation. This patient required venoarterial extracorporeal membrane oxygenation for ventricular support 36 hours after the operation and died on the third postoperative day. The other patient, from the con- 
Table II. Patient diagnosis, operation, and modified ultrafiltration details

\begin{tabular}{lccc}
\hline & MUF group & Control group & $p$ Value \\
\hline VSD & 7 & 5 & 0.62 \\
TGA & 2 & 2 & 1.0 \\
TOF & 1 & 2 & 0.72 \\
Other & 1 & 1 & 1.0 \\
Total No. of patients & 11 & 10 & 0.58 \\
CPB (range) (min) & $106 \pm 32(73-150)$ & $92 \pm 21(61-133)$ & 0.06 \\
Crossclamp (range) (min) & $59 \pm 25(20-92)$ & $40 \pm 14(19-69)$ & 0.09 \\
Filtrate volume (ml) & - & - \\
Hematocrit (\%) (T1) & $363 \pm 262$ & $29.3 \pm 2.6$ & 0.07 \\
Hematocrit (\%) (T2) & $26.0 \pm 2.7$ & $30.7 \pm 2.6 \dagger$ & 0.001 \\
\hline
\end{tabular}

$V S D$, Ventricular septal defect; TGA, transposition of the great arteries; TOF, tetralogy of Fallot; $C P B$, cardiopulmonary bypass; MUF, modified ultrafiltration. $p$ Value, Unpaired $t$ test, MUF group versus control group.

${ }^{*} p=0.018, \mathrm{~T} 1$ versus $\mathrm{T} 2$ for MUF group.

$\dagger p=0.08$, T1 versus $\mathrm{T} 2$ for control group.

Table III. Recorded parameters at T1 and T2 for the MUF and control groups

\begin{tabular}{|c|c|c|c|c|c|c|c|c|}
\hline & \multicolumn{3}{|c|}{ MUF group } & \multicolumn{3}{|c|}{ Control group } & \multirow{2}{*}{$\begin{array}{c}T 1_{\text {MUF }} \text { vs } \\
T 1_{\text {control }} \\
p \\
\end{array}$} & \multirow{2}{*}{$\begin{array}{c}T 2_{\text {MUF }} \text { vs } \\
T 2_{\text {control }} \\
p\end{array}$} \\
\hline & $T 1$ & $T 2$ & $p$ & $T 1$ & $T 2$ & $p$ & & \\
\hline HR (beats/min) & $144 \pm 26$ & $145 \pm 24$ & 1.0 & $161 \pm 30$ & $157 \pm 33$ & 0.38 & 0.21 & 0.37 \\
\hline $\operatorname{EDL}(\mathrm{mm})$ & $25.6 \pm 9.0$ & $28.8 \pm 9.9$ & 0.01 & $31.8 \pm 7.0$ & $31.6 \pm 7.2$ & 0.57 & 0.16 & 0.49 \\
\hline $\mathrm{EDP}(\mathrm{mm} \mathrm{Hg})$ & $5.6 \pm 0.8$ & $4.2 \pm 0.8$ & 0.005 & $5.5 \pm 0.4$ & $5.6 \pm 0.4$ & 0.85 & 0.69 & 0.002 \\
\hline MEP (mm Hg) & $58.3 \pm 25.2$ & $70.3 \pm 23.4$ & 0.001 & $80.2 \pm 15.5$ & $72.5 \pm 10.2$ & 0.22 & 0.02 & 0.77 \\
\hline Wall thickness (mm) & $6.8 \pm 1.7$ & $5.8 \pm 0.5$ & 0.04 & $6.5 \pm 0.9$ & $6.6 \pm 0.8$ & 0.88 & 0.66 & 0.05 \\
\hline Myocardial CSA $\left(\mathrm{cm}^{2}\right)$ & $3.72 \pm 0.35$ & $3.63 \pm 0.36$ & 0.04 & $3.45 \pm 0.27$ & $3.55 \pm 0.33$ & 0.09 & 0.02 & 0.45 \\
\hline
\end{tabular}

$H R$, Heart rate; $E D L$, end-diastolic length; $E D P$, end-diastolic pressure; $M E P$, mean ejection pressure; $C S A$, cross-sectional area. $p$, paired $t$ test, T1 versus $\mathrm{T} 2$; unpaired $t$ test, $\mathrm{T}_{\text {MUF }}$ versus $\mathrm{T}_{\text {control. }}$.

trol group, died 24 days after the operation, having been discharged from hospital on day 7.

Patients in the MUF group received less inotropic drug support in the first 24 hours after the operation $(156.62 \pm 92.31 \mu \mathrm{g} / \mathrm{kg}$ in 24 hours) than patients in the control group $(865.33 \pm 1772.26 \mu \mathrm{g} / \mathrm{kg}$ in 24 hours, $p=0.03$ ). All the patients in the MUF group received dopamine for at least 11 hours after the operation, and three required dobutamine. All but two of the patients in the control group received dopamine. Four patients in the control group received dobutamine, two received epinephrine, and one received milrinone. The doses of inotropic agents received in the first 24 hours after the operation were fairly standard in the MUF group but showed a large variation in the control group.

Two patients in the control group had delayed closure of their sternotomy incision. One incision remained open for 6 days and the other for 3 days before being closed. In the MUF group, one patient had the sternum left open at the end of the operation and that was the patient who died in the intensive care unit 3 days later.
Both groups were ventilated for a similar number of hours (24 \pm 36 hours in the MUF group and $26 \pm$ 19 hours in the control group) and remained in the intensive care unit for a similar mean number of days ( $4 \pm 4$ and $4 \pm 3$ days, respectively).

\section{Discussion}

This study has demonstrated that the hemodynamic improvements seen after modified ultrafiltration are associated with an increase in intrinsic left ventricular systolic function. The increase in enddiastolic length and fall in end-diastolic pressure seen after modified ultrafiltration is consistent with an improvement in left ventricular compliance resulting from a reduction in myocardial edema.

Modified ultrafiltration was first described by Naik, Knight, and Elliott ${ }^{7}$ in 1991 and was shown to be more effective than conventional ultrafiltration in reducing the rise in total body water and in elevating hematocrit value after CPB. It was also shown to reduce the donor blood requirement associated with CPB in children. ${ }^{10}$ Several studies have shown an improvement in hemodynamic parameters after 
MUF group
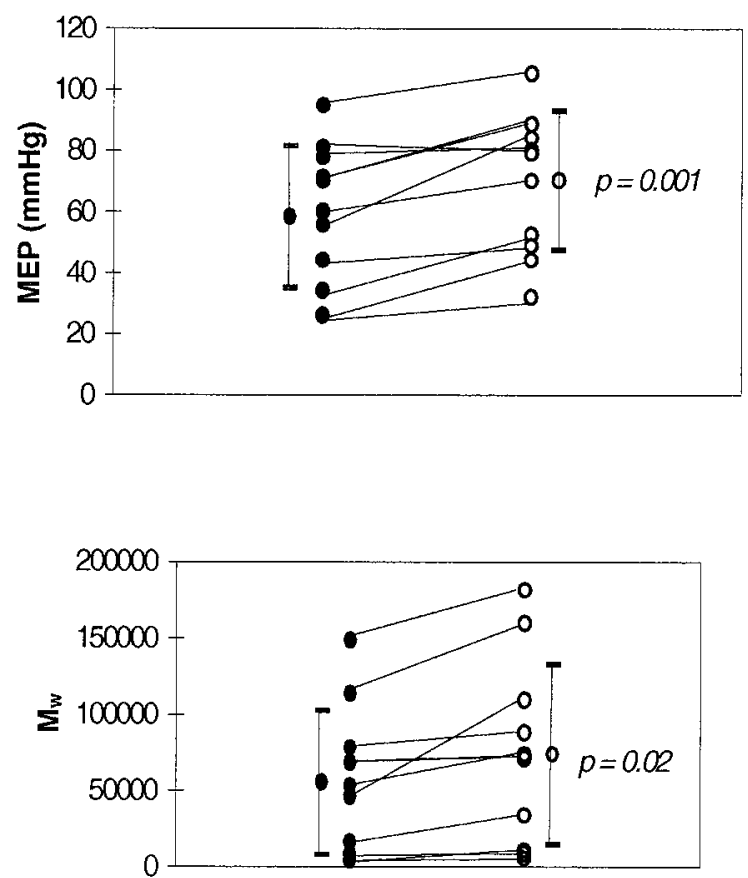

\section{Control group}
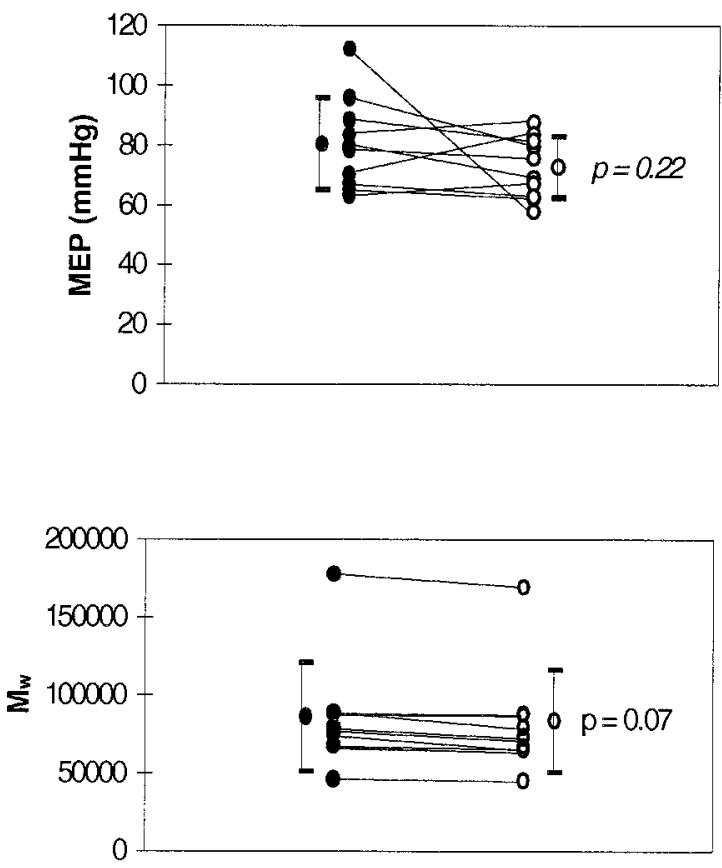

Fig. 2. Changes in mean ejection pressure, stroke length, shortening fraction index, and preloadrecruitable stroke work index from T1 to T2 in the MUF and control groups of patients. Closed circles, T1; open circles, T2. Mean \pm 1 standard deviation. MEP, Mean ejection pressure; $M_{W}$, slope of the preload-recruitable stroke work index.

Table IV. Slope and $x$-axis intercepts of the preloadrecruitable stroke work index for the groups

\begin{tabular}{lccc}
\hline & $\begin{array}{c}M_{W} \mathrm{T1} \\
\left(10^{3} \mathrm{erg} / \mathrm{cm}^{3}\right)\end{array}$ & $\begin{array}{c}M_{W} \mathrm{T2} \\
\left(10^{3} \mathrm{erg} / \mathrm{cm}^{3}\right)\end{array}$ & $p$ Value \\
\hline MUF group & $52.3 \pm 52.0$ & $74.2 \pm 66.0$ & 0.02 \\
Control group & $89.0 \pm 57.4^{*}$ & $88.1 \pm 57.1$ & 0.07 \\
\hline & $L_{W} T 1$ & $L_{W} T 2$ & $p$ Value \\
\hline MUF group & $25.8 \pm 10.6$ & $26.3 \pm 10.7$ & 0.46 \\
Control group & $26.7 \pm 5.1$ & $26.6 \pm 5.6$ & 0.64
\end{tabular}

$M_{W}$, Slope of the preload/recruitable stroke work index; $L_{W}$, x-axis intercept of the preload-recruitable stroke work index; MUF, modified ultrafiltration.

${ }^{*} p=0.053 ;$ T1 MUF versus T1 control. $p$ value, paired $t$ test, T1 versus T2.

modified ultrafiltration. ${ }^{10,18,19}$ Naik's group observed a rise in blood pressure in all patients and also noticed that the heart became visibly smaller during modified ultrafiltration. They believed that this may be due to a simultaneous reduction in pulmonary vascular resistance and myocardial water content. Gaynor and associates ${ }^{12}$ confirmed the reduction in myocardial cross-sectional area after modified ultrafiltration. A study by Hodges and associates ${ }^{19}$ also confirmed a rise in systemic arterial pressure and cardiac index after modified ultrafiltration, and they also showed that this was not associated with a change in plasma fentanyl level. Later studies ${ }^{4}$ have shown that systemic vascular resistance is not significantly changed during modified ultrafiltration, but there is a decrease in heart rate and a dramatic decrease in pulmonary vascular resistance. Hence we hypothesized that the hemodynamic changes seen after modified ultrafiltration were due to improvements in myocardial contractility associated with a reduction in myocardial water content.

The preload-recruitable stroke work index used in this study was first described by Glower and colleagues $^{13}$ in 1985 as a load-insensitive index of left ventricular systolic function. Subsequent studies have confirmed this relationship to be a highly reproducible, linear index of left ventricular systolic function in adult human beings ${ }^{20}$ and recently in neonates. ${ }^{21,22}$ Use of the preload-recruitable stroke work index, using a single dimension (minor axis) to determine an index of stroke work, has been previ- 

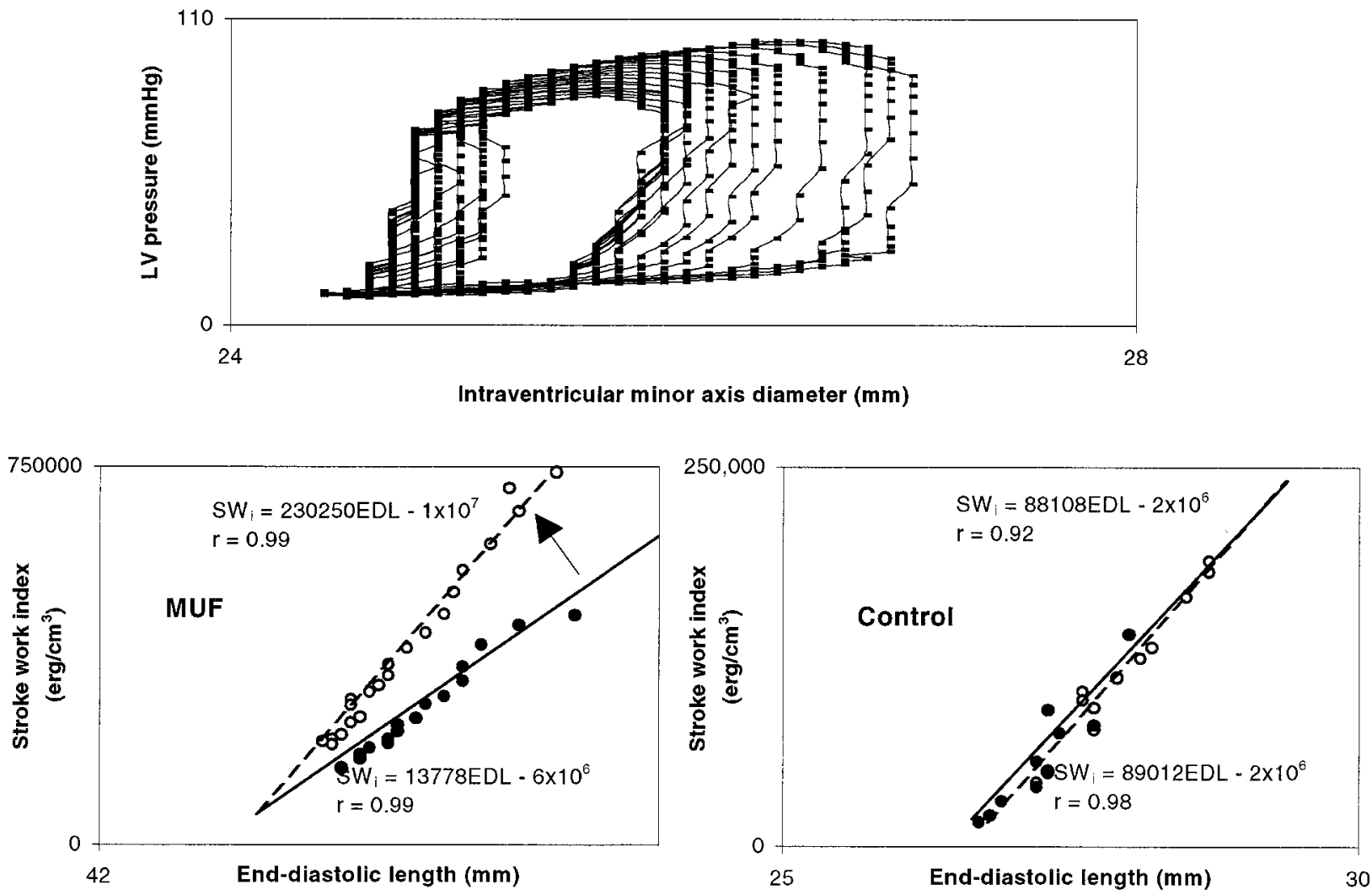

Fig. 3. Representative set of pressure-dimension loops with representative changes in preload-recruitable stroke work index from T1 to T2. Closed circles, T1; open circles, T2; LV, left ventricular; MUF, modified ultrafiltration; $S W_{\dot{v}}$ stroke work index; $E D L$, end-diastolic length; $r$, regression index.

ously validated in animal studies ${ }^{13,23}$ and used in human studies ${ }^{21}$ as a load-independent index of ventricular contractility.

The data presented from this study confirm the improved hemodynamics seen after modified ultrafiltration in other studies. ${ }^{10,18,19}$ We have demonstrated that the improvement in hemodynamics is due to an increase in intrinsic left ventricular systolic function, as shown by the increase in preloadrecruitable stroke work index (Figs. 2 and 3, Table IV). After CPB, the MUF group had a more depressed left ventricular systolic function than the control patients. The mean ejection pressure and preload-recruitable stoke work index were significantly lower and the myocardial cross-sectional area was significantly higher in the MUF group (Table III). This may have been due to the longer CPB and crossclamp times in the MUF group (Table II), but the difference failed to reach statistical significance.

Despite the initially depressed ventricular function in the MUF group, there was no difference between the two groups after ultrafiltration (Tables III and IV), and the MUF group received significantly less inotropic support in the first 24 hours after the operation. This difference did not persist beyond the first postoperative day, presumably because of a multiplicity of variables.

This study has demonstrated a reduction in myocardial wall thickness and cross-sectional area (myocardial wall volume) after modified ultrafiltration. These reductions presumably are due to a reduction in myocardial edema, which was not seen in the control patients (Table III). The reduction in myocardial edema is associated with an increase in end-diastolic length and a fall in end-diastolic pressure (Table III). These changes are consistent with improved left ventricular diastolic compliance after modified ultrafiltration.

The improvement in hemodynamics seen in all patients after modified ultrafiltration is reflected by the increase in preload-recruitable stroke work index also seen in these patients (Fig. 3). This increase in 
left ventricular systolic function may be due to a reduction in myocardial edema, which would correlate with the fall in total body water seen in previous studies. ${ }^{7,10}$ The reduction in myocardial edema seen in this study is associated with an improvement in left ventricular diastolic compliance and an improved intrinsic systolic function. However, it could be associated with the increase in hematocrit value seen after modified ultrafiltration (Table II), with an associated increase in oxygen delivery. ${ }^{24}$ Oxygen delivery was not examined in this protocol. However, if this was the case it is difficult to match this with the significant improvement in left ventricular systolic function that appears to be continued, at least for the first 24 hours after operation. We elected not to transfuse the control patients up to a hematocrit value equal to that of the MUF patients, because this is unlikely to have resolved the left ventricular myocardial edema. A separate study would be needed to address this issue.

The hemodynamic improvements may also be related to modification of the inflammatory response to CPB and ischemia. ${ }^{4,5,25}$ However, the time course for improvement in left ventricular systolic function weighs against this hypothesis. Similarly, we could not test for changes in colloid osmotic pressure with this group of patients. Such a test would require further investigation.

This study was conducted in patients undergoing hypothermic, hemodiluted CPB with crystalloid cardioplegia, which may all contribute to tissue edema and specifically myocardial edema. It will be interesting to observe whether warm CPB and blood cardioplegia can result in less myocardial edema and an improvement in post-CPB left ventricular systolic function. A separate study is required for this.

This study did not address the issue of conventional ultrafiltration compared with modified ultrafiltration. Time constraints prevented the addition of a third group. However, in our clinical practice, if hemodilution and hypothermia are used, as in this study, we routinely use conventional ultrafiltration during CPB to increase the hematocrit value toward $30 \%$ (T1 values, Table II), but this was not controlled in this study. Previous studies have shown that conventional ultrafiltration fails to reverse satisfactorily hemodilution and the rise in total body water seen after CPB. ${ }^{7,}{ }^{10}$ Modified ultrafiltration is used after CPB to complete the increase in hematocrit value and achieve maximum benefits from other aspects of its action. ${ }^{4,7}$

One limitation of this study is that, despite the randomization, the MUF group had a suppressed left ventricular systolic function at time T1. However, after modified ultrafiltration, left ventricular function improved toward that of the control group (Table IV). We could not have controlled for this or for the difference in $\mathrm{CPB}$ and crossclamp times. Blinding was also lost when the patients returned to the intensive care unit. Although these factors may have contributed to the difference in delivery of inotropic agents during the first 24 hours after operation, we do not believe that this was the case, because the intensive care management is handled by a separate intensive care team.

In summary, use of modified ultrafiltration after hypothermic, hemodiluted CPB improves intrinsic left ventricular systolic function, reduces myocardial edema, improves left ventricular compliance, increases blood pressure, and decreases inotropic drug use in the early postoperative period.

\section{REFERENCES}

1. Kirklin JK, Blackstone EH, Kirklin JW. Cardiopulmonary bypass: studies on its damaging effects. Blood Purif 1987;5: 168-78.

2. Maehara T, Novak I, Wyse RKH, Elliott MJ. Perioperative monitoring of total body water by bioelectrical impedance in children undergoing open heart surgery. Eur J Cardiothorac Surg 1991;5:258-65.

3. Millar AB, Armstrong L, van der Linden J, Moat N, Ekroth $\mathrm{R}$, Westwick J, et al. Cytokine production and hemofiltration in children undergoing cardiopulmonary bypass. Ann Thorac Surg 1993;56:1499-502.

4. Elliott MJ. Ultrafiltration and modified ultrafiltration in pediatric open heart operations. Ann Thorac Surg 1993;56: 1518-22.

5. Andreasson S, Gothberg S, Berggren H, Bengsson A, Eriksson E, Risberg B. Hemofiltration modifies complement activation after extracorporeal circulation in infants. Ann Thorac Surg 1993;56:1515-7.

6. Brans YW, Dweck HS, Havis HB, Park GVS, Bailey PE, Kirklin JW, et al. Effects of open heart surgery on the body composition of infants and young children. Pediatr Res 1981;15:1024-8.

7. Naik SK, Knight A, Elliott MJ. A successful modification of ultrafiltration for cardiopulmonary bypass. Perfusion 1991;6: 41-50.

8. Laks H, Standeven J, Blair O, Hahn J, Jellinek M, Willman VL. The effects of cardiopulmonary bypass with crystalloid and colloid hemodilution on myocardial extravascular water. J Thorac Cardiovasc Surg 1977;73:129-34.

9. Kopman EA, Ferguson TB. Pulmonary edema following cardiopulmonary bypass. Anesth Analg 1978;57:367-70.

10. Naik SK, Knight A, Elliott MJ. A prospective randomized study of a modified technique of ultrafiltration during pediatric open-heart surgery. Circulation 1991;84(Suppl):III42231.

11. Journois D, Israel-Biet D, Pouard P, Rolland B, Silvester W, Vouche P, et al. High-volume, zero-balanced hemofiltration 
to reduce delayed inflammatory response to cardiopulmonary bypass in children. Anesthesiology 1996;85:965-76.

12. Gaynor JW, Tulloch RMR, Owen CH, Sullivan ID, Elliott MJ. Modified ultrafiltration reduces myocardial edema and reverses hemodilution following cardiopulmonary bypass in children [abstract]. J Am Coll Cardiol 1995;25:200A.

13. Glower DD, Spratt JA, Snow ND, Kabas JS, Davis JW, Olsen $\mathrm{CO}$, et al. Linearity of the Frank-Starling relationship in the intact heart: the concept of preload recruitable stroke work. Circulation 1985;71:994-1009.

14. Heinle J, Lodge A, Mault J, Whitaker E, Ungerleider R. Geometric modeling of the neonatal left ventricle [abstract]. J Am Coll Cardiol 1993;21:475A.

15. Rankin JS, McHale PA, Arentze CE, Ling O, Greenfield JC $\mathrm{Jr}$, Anderson RW. The three dimensional dynamic geometry of the left ventricle in the conscious dog. Circ Res 1976;39: 304-13.

16. Stark J, de Leval M, editors. Surgery for congenital heart defects. 2nd ed. Philadelphia: WB Saunders; 1994.

17. Wernovsky G, Wypij D, Jonas RA, Mayer JE Jr, Hanley FL, Hickey PR, et al. Postoperative course and hemodynamic profile after the arterial switch operation in neonates and infants: a comparison of low-flow cardiopulmonary bypass and circulatory arrest. Circulation 1995;92:2226-35.

18. Darling EM, Shearer IR, Nanry K, Kern FH, Greeley WJ, Ungerleider RM, et al. Modified ultrafiltration in pediatric cardiopulmonary bypass. J Extracorp Technol 1994;26:205-9.

19. Hodges UM, Berg S, Naik SK, Bower S, Lloyd-Thomas A, Elliott M. Filtration of fentanyl is not the cause of the elevation of arterial blood pressure associated with postbypass ultrafiltration in children. J Cardiothorac Vasc Anesth 1994;8:653-7.

20. Takeuchi M, Odake M, Takaoka H, Hayashi Y, Yokoyama M. Comparison between preload recruitable stroke work and the end-systolic pressure-volume relationship in man. Eur Heart J 1992;13(Suppl E):80-4.

21. Blatchford JW, Barragry TP, Lillehei TJ, Ring WS. Effects of cardioplegic arrest on left ventricular systolic and diastolic function of the intact neonatal heart. J Thorac Cardiovasc Surg 1994;107:527-35.

22. Davies MJ, Quarterman RL, Tsui SSL, Jacobs MT, Davis JW, Elliott MJ, et al. Comparison of three indexes of contractility in the neonatal left ventricle. Cardiovasc Eng 1997;2:180-90.

23. Morris JD, Pellom G, Murphy C, Salter D, Goldstein J, Wechsler A. Quantification of the contractile response to injury: assessment of the work-length relationship in the intact heart. Circulation 1987;76:717-27.

24. Skaryak LA, Kirshbom PM, DiBernardo LR, Kern FH, Greeley WJ, Ungerleider RM, et al. Modified ultrafiltration improves cerebral metabolic recovery after circulatory arrest. J Thorac Cardiovasc Surg 1995;109:744-51.

25. Finn A, Naik S, Klein N, Levinsky RJ, Strobel S, Elliott MJ. Interleukin-8 release and neutrophil degranulation after pediatric cardiopulmonary bypass. J Thorac Cardiovasc Surg 1993;105:234-41.

\section{Discussion}

Dr. Patricia A. Penkoske (Edmonton, Alberta, Canada). I rise to compliment the authors on this effort to delineate the mechanism by which modified ultrafiltration increases cardiac index and systolic blood pressure in a clinical setting. Since described by Naik and associates in 1991, this technique has been reported to improve postoperative hemodynamics, increase pulmonary compliance, and decrease bleeding clinically. At the meeting of the Society of Thoracic Surgeons, Dr. Spray and his group recently extended its efficacy to the cavopulmonary anastomosis and the Norwood procedure. Dr. Bando, at the current meeting, described a beneficial effect on the pulmonary vasculature related to the removal of plasma endothelin-1, and experimentally Dr. Ungerleider has reported a reduction of brain injury with its use after deep hypothermic circulatory arrest.

This study elegantly uses Millar catheters, myocardial ultrasonic crystals, and echocardiography, in addition to an inotropic support score, in the clinical setting to try to quantitate various parameters of systolic and diastolic function after $\mathrm{CPB}$ in the infant age group.

I have three questions. Despite well-matched ages, CPB times, and cross-clamp times, the mean ejection pressures of the experimental group at $\mathrm{T} 1$ are quite low, and quite a bit lower than those of the control group. Pressure in the experimental group is $58 \mathrm{~mm} \mathrm{Hg}$ and in the control group, $80 \mathrm{~mm} \mathrm{Hg}$; actually, in the experimental group some pressures were as low as $20 \mathrm{~mm} \mathrm{Hg}$. What is the reason for this decrease in the baseline? Also, does this lower baseline in the experimental group contribute to the perceived increase in blood pressure?

Second, you have vast experience with ultrafiltration. Are there any contraindications to this technique?

Last, you mentioned that the decrease in inotropic requirement with ultrafiltration is not a sustained decrease. A slump in myocardial performance does seem to occur several hours after return to the intensive care unit. Do you have any ideas about a potential type of rebound with some of these mediators that you are removing? Can you give us your ideas about the role of this type of technique or a similar technique in the intensive care unit setting?

Dr. Davies. Thank you, Dr. Penkoske. Despite randomization, the patients in the MUF group did have a lower mean ejection pressure coming off CPB. Why this was so is difficult to say, although that group did have slightly longer CPB and crossclamp times. The difference in CPB times almost reached statistical significance. $\mathrm{CPB}$ and operative techniques were standardized as much as possible across all operations.

The rise in mean ejection pressure after modified ultrafiltration, each patient acting as his or her own control, was observed across all patients. There was no rise in pressure in the control group. At time T2 there was no statistically significant difference between the MUF group and the control group, although at time T1, when the patients were first weaned from CPB, the MUF group did have a lower mean ejection pressure.

In response to your second question about contraindications to modified ultrafiltration, we use modified ultrafiltration in the majority of our bypass cases. Dr. Gaynor has conducted a straw poll at this meeting, and the majority of physicians in the poll use modified ultrafiltration in some or all of their operations. We do not use ultrafiltration when the $\mathrm{CPB}$ time is very short; atrial septal defects are an obvious example of cases in which 
the operation is shorter than the ultrafiltration time. We also avoid ultrafiltration if the aortic cannula causes obstructive flow when the patient is being weaned from $\mathrm{CPB}$. In that case, to improve the situation, we remove the cannula.

Inotropic requirements: We looked at inotropic requirements over 24 hours after the operation. We did not conduct a detailed, blinded analysis. We merely noted that the patients who had had filtration required less inotropic support, and this was maintained for 24 hours. After that, the length of time in the intensive treatment unit and the days to discharge from hospital were much the same, although the intensive treatment unit stay was shorter in the ultrafiltration group. This difference also did not reach statistical significance.

You commented on postoperative rebound in the intensive care unit. We have not yet looked at this, although we do intend to continue these studies and measure ventricular contractility into the postoperative period. At the moment we are modifying the epicardial crystals so that we can remove them after the operation, just like pacing wires, and we will be measuring contractility in the postoperative period. It will be interesting to see what happens. Until we have the results of that study, I am unable to comment.
Dr. Casey W. Daggett (Durham, N.C.). Have you found any differences with regard to pulmonary hemodynamics in your study?

In terms of diastolic function, you suggest that myocardial edema decreases, but did you notice any differences in either the diastolic function and the pressure-volume relationship or the $\mathrm{x}$-intercept on your pressure-volume dimensions?

Dr. Davies. We did not look at pulmonary hemodynamics in this study. This study was principally to evaluate myocardial contractility. We have shown from Great Ormond Street in previous studies that pulmonary vascular resistance is reduced after ultrafiltration.

We suggest from this study that there is an improvement in diastolic compliance with the increase in enddiastolic length and the reduction in end-diastolic pressure. We have not yet evaluated this in relation to the pressure-dimension loops. There is no statistically significant change in the $\mathrm{x}$-intercept.

Dr. Daggett. There seemed to be a large standard deviation in the postoperative hematocrit values in your patients. Did you find that the patients who tended to have a higher hematocrit value also had improved contractility?

Dr. Davies. We did not look specifically at that question, but it does need to be answered. 